\title{
Karakteristik Limbah Daun Tebu Sebagai Sumber Energi Baru Terbarukan Berbasis Densification Method
}

\author{
Asroful Anam ${ }^{1 *}$, Muhammad Azizul Majid ${ }^{2}$ \\ ${ }^{1}$ Teknik Mesin S-1, Institut Teknologi Nasional Malang \\ Jl. Raya karanglo KM 2 Malang \\ ${ }^{2}$ Teknik Mesin S-1, Institut Teknologi Nasional Malang \\ Jl. Sigura-gura No. 2 Malang \\ *E-mail: asrofulan@gmail.com
}

\begin{abstract}
Abstrak
Bahan bakar fosil merupakan bahan bakar alam yang tidak dapat diperbaruhi dan persediaannya akan segera habis jika digunakan secara terus menerus dalam skala besar untuk memenuhi kebutuhan energi. Sehingga pemanfaatan bahan bakar alternatif sebagai sumber energi baru mutlak diperlukan, terlebih bahan bakar tersebut persediaanya melimpah dan dapat diperbarui, seperti biomassa limbah industri atau limbah pertanian. Bahan bakar biomassa adalah salah satu sumber energi yang telah banyak dikembangkan dan diteliti sebagai bahan bakar pengganti batubara dengan berbagai perlakuan dan proses yaitu untuk mendapatkan jenis bahan bakar biomassa yang menyamai kualitas batubara. Penelitian ini menyuguhkan penelitian biomassa dari limbah daun tebu dengan metode densifikasi dengan penambahan perekat minyak kayu kapas. Metode densifikasi pada penelitian ini diikuti dengan metode eksperimental dengan memvariasikan ukuran serbuk daun tebu (DT) dan campuran serbuk daun dengan perekat (DTP). Variasi DT adalah $1 \mathrm{~mm}, 1.5 \mathrm{~mm}$, dan 2 mm dengan DTP 200 gram : 1 gram, 200 gram : 2 gram, dan 200 gram : 3 gram. Tujuan penelitian adalah untuk mengetahui nilai kalor, kadar abu, dan kadar air dengan dampak penelitian yang hendak dicapai adalah limbah daun tebu bisa dijadikan sebagai bahan bakar baru terbarukan dan bisa mengurangi masalah bagi petani. Berdasarkan data hasil penelitian menunjukan bahwa nilai kalor tertinggi pada DT $2 \mathrm{~mm}$, yaitu 3975,01 cal/gr pada DTP 1 dan terendah pada DT $1.5 \mathrm{~mm}$ yaitu 2441,67 cal/gr pada DTP 2; kadar abu tertinggi pada DT $1 \mathrm{~mm}, 13,66 \%$ pada DTP 1 dan terendah pada DT $2 \mathrm{~mm}$, yaitu 6,6\% pada DTP 3 dan kadar air tertinggi pada DT $1 \mathrm{~mm}$, yaitu 9,8\% pada DTP 2 dan terendah pada DT 2 mm, yaitu 7,6\% pada DTP 3. Kesimpulan penelitian ini adalah ukuran serbuk dau tebu dan variasi campuran serbuk daun tebu dengan perekat minyak biji kapas mempengaruhi karakteristik limbah daun tebu sebagai sumber energi baru terbarukan.
\end{abstract}

Received: 23-03-2020; Accepted: 16-04-2020; Published online: 23-04-2020

Kata kunci: Biomassa; daun tebu; densifikasi; kadar

\begin{abstract}
Fossil fuels are natural fuels that cannot be renewed and their supplies will soon run out if used continuously on a large scale to meet energy needs. In order to alternative fuels are absolutely necessary, such as industrial waste or agricultural biomass. Biomass fuels are being developed and researched with various treatments to obtain a type of fuel that matches the quality of coal by using many treatments to obtain the same quality as the coal. This paper presents biomass research from sugarcane leaf waste with the addition of cottonwood oil adhesive. The investigation method was a densification process and being followed by an experimental method by varying the size of sugarcane leaf powder (DT), namely $1 \mathrm{~mm}, 1.5 \mathrm{~mm}$, and $2 \mathrm{~mm}$; and the ratio of the sugarcane leaf powder with cottonwood oil adhesive (DTP) werethe DTP (200 grams) with 1 gram, 2 grams, and 3 grams. The aim of this study was to determine the heating value, ash content, and water moisture. Based on the research data, it shows that the highest and lowest heating values are DT $2 \mathrm{~mm}, 3975.01 \mathrm{cal} / \mathrm{gr}$ on DTP 1 and DT $1.5 \mathrm{~mm}, 2441.67 \mathrm{cal} / \mathrm{gr}$ on DTP 2 respectively; the highest and lowest ash contents are DT $1 \mathrm{~mm}, 13,66 \%$ on DTP 1 and DT $2 \mathrm{~mm}, 6,6 \%$ on DTP 3 respectively; and the highest and lowest water moistures are DT $1 \mathrm{~mm}, 9,8 \%$ on DTP 2 and DT $2 \mathrm{~mm}, 7,6 \%$ on DTP 3 serially. The conclusion is the variations in the size of the sugarcane leaf powder and the ratio of the sugarcane leaf powder with with cottonwood oil adhesive affect characteristics of sugarcane leaf waste as a renewable energy source.
\end{abstract}

Keywords: Fuels; grams; powder; sugarcane leaf

\section{Pendahuluan}

Bahan bakar fosil misalnya batubara merupakan bahan bakar alam dan sumber energi yang tidak dapat diperbaruhi dan merupakan bahan bakar mineral yang mengandung hidrokarbon. Sehingga, pada penggunaanya menyisakan zat karbon dioksida tinggi yang dapat mencemari lingkungan dan menyebabkan pemanasan global. Penggunaan bahan 
bakar batubara dalam memenuhi kebutuhan energi telah dibatasi karena memiliki dampak buruk bagi lingkungan, terutama penggunakan dalam skala besar yang persediaanya akan habis di alam. Sehingga pemanfaatan sumber energi alternatif yang potensinya melimpah dan dapat diperbaruhi mutlak diperlukan agar kebutuhan energi tetap terpenuhi, baik untuk memenuhi kebutuhan energi masyarakat industri maupun masyarakat umum. Di Indonesia potensi sumber energi baru terbarukan sangat melimpah, misalnya: sumber energi air, angin, dan biomassa. Seperti yang disampaikan oleh Kepala Bagian Komunikasi dan Layanan Informasi Biro KLIK Kementerian ESDM [1] bahwa potensi energi baru terbarukan di Indonesia adalah $400 \mathrm{GW}$ dan baru dimanfaatkan sekitar $1 \mathrm{GW}$, termasuk pemanfaatan biomassa sebagai pengganti batubara yang potensinya mencapai $50 \mathrm{GW}$.

Biomassa sebagai pengganti batubara adalah bahan bakar yang berasal campuran bahan organik yang kompleks, terdiri dari: karbohidrat, lemak, protein dan mineral lain yang jumlahnya sedikit seperti sodium, fosfor, kalsium dan besi [2]. Merujuk pada data Kementrian ESDM dan program pengembangan EBT [3] tentang Kebijakan Energi Nasional bahwa pembangkit listrik dengan bahan bakar biomassa sebesar 180 MW pada tahun 2020, maka pemerintah mendorong agar ada upaya integrasi untuk mengembangkan dan meningkatkan penelitian tentang pemanfaatn limbah industri, kehutanan, dan limbah pertanian untuk menghasilkan energi. Penelitian biomassa limbah industri dan limbah pertanian telah banyak dilakukan oleh peneliti, seperti penelitian limbah serbuk gergaji kayu jati dan kulit kacang [4], penelitian perbandingan berbagai limbah biomassa [5], pemanfaatan daun tebu sebagai sumber bioenergi di Filipina [6], kinetika degradasi bahan bakar biomassa daun tebu [7] dan karakteristik daun tebu sebagai bahan bakar padat [8]. Penelitian-penelitian tersebut merupakan penelitian biomassa yang tujuan utamanya adalah mendapatkan jenis bahan bakar biomassa yang dapat menyamai kualitas bahan bakar batubara karena sifat biomassa berbeda dengan karateristik batubara, khususnya batubara yang berasal dari Indonesia yang memiliki kualitas yang sangat baik yaitu memiliki nilai kalor kisaran 6400-6900 kkal/kg dengan kadar abu 8-15\%; kadar air total 4-12\%; volatile matter 37,3-41,5\%; dan belerang 0,50-0,80\% [9].

Beberapa sifat biomassa antara lain dapat diperbaharui (renewable resources), relatif tidak mengandung unsur sulfur, sehingga tidak menyebabkan polusi udara dan juga dapat meningkatkan efisiensi pemanfaatan sumber daya hutan dan pertanian [10]. Akan tetapi, biomassa yang digunakan secara langsung sebagai bahan bakar kurang efisien, sehingga biomassa jenis apapun perlu diberi perlakuan proses atau di treatment melalui uji eksperimen, semisal limbah daun tebu pada penelitian ini. Penelitian yang dilakukan adalah penelitian biomassa limbah pertanian tebu berupa limbah daun yang selama ini menjadi masalah bagi petani ketika lahan pertaniannya akan diolah kembali untuk menumbuhkan tunas-tunas baru. Sehingga, penelitian limbah daun tebu sebagai biomassa sangat penting dilakukan, disamping untuk mendukung program pemerintah dan membantu para petani tebu mengatasi masalah limbahnya. Sebelum dilakukan penelitian limbah daun tebu sebagai biomassa, petani biasanya membakar limbah daun tebunya dan sebagian bahan bakar langsung pembuatan batu bata, walaupun pada penyimpanannya membutuhkan banyak tempat dan rentan terhadap kebakaran. Dengan penelitian limbah daun tebu sebagai bahan bakar biomassa, para petani terbantu mengatasi masalahnya dan limbah daun tebu bisa menjadi salah satu jenis biomassa yang handal karena memilik karakteristik yang baik dan potensinya juga melimpah sebagai salah satu sumber energi terbarukan.

Metode penelitian limbah daun tebu yang digunakan adalah proses densifikasi jenis peletisasi seperti yang pernah dilakukan oleh peneliti sebelumnya yaitu penelitian bahan bakar biomassa non daun tebu dengan tujuan penelitian adalah untuk meningkatkan densitas dan menurunkan persoalan penanganan seperti penyimpanan dan pengangkutan [11]. Kemudian metode densifikasi pada penelitian ini diikuti dengan metode eksperimen pada variasi ukuran serbuk daun tebu dan variasi pencampuran antara masing-masing ukuran serbuk daun tebu dengan perekat dengan 
perbandingan tertentu. Penggunaan metode densifikasi jenis pelet, eksperimental dan perekat pada pelet daun tebu didasarkan pada penelitian-penelitian sebelumnya dan yang membedakan adalah pada variasi ukuran serbuk dan rasio perbandingan antara biomassa dan perekat. Penggunaan metode dan perekat juga berkaitan dengan tujuan dari penelitian ini dilakukan yaitu untuk mendapatkan jenis biomassa yang memiliki karakteristik dan kualitas yang baik berupa nilai kalor, kadar abu dan kadar air yang menyamai batubara.

\section{Material dan metodologi}

\subsection{Bahan dan peralatan}

Bahan daun tebu (sugarcane leaf) pada penelitian ini diambil dari lahan-lahan pertanian tebu yang berada di Malang, Jawa Timur yang jumlahnya sangat banyak. Kemudian daun tebu dicacah menjadi ukuran kecil sebelum di giling menjadi ukuran serbuk pada mesin penggiling dan di saring untuk mendapatkan serbuk daun tebu yang diinginkan dan selanjutnya dibentuk pelet. Mesin penggiling pada penelitian ini seperti tampak pada Gambar 1(a) yang memiliki beberapa komponen yakni motor penggerak, pulley, van belt, control switch on/off dan satu set tempat untuk penggilingan. Sedangkan alat pengepresan pelet serbuk daun tebu seperti tampak pada Gambar 1(b), dengan menggunakan sistem hidrolik sebagai penggerak mesin pres dengan komponen, yaitu solenoid valve, pressure gauge, pressure valve, dan controller. Prinsip kerja alat pengepresan pelet adalah tekanan diatur pressure valve, solenoid digunakan untuk mengatur naik turun piston pres, controller berfungsi sebagai penggerak solenoid pressure gauge digunakan untuk mengetahui tekanan pengepresan. Sedangkan beberapa alat bantu yang digunakan adalah burner pellet, termokopel, stopwatch, timbangan digital, moisture meter, dan cetakan pelet.

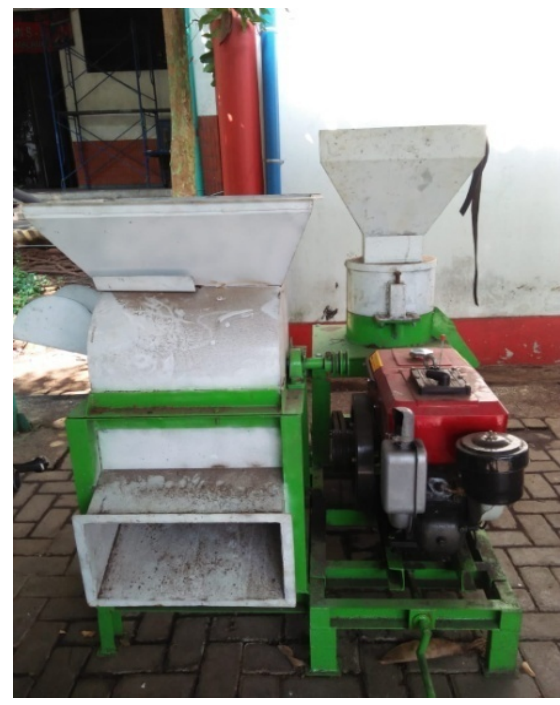

(a)

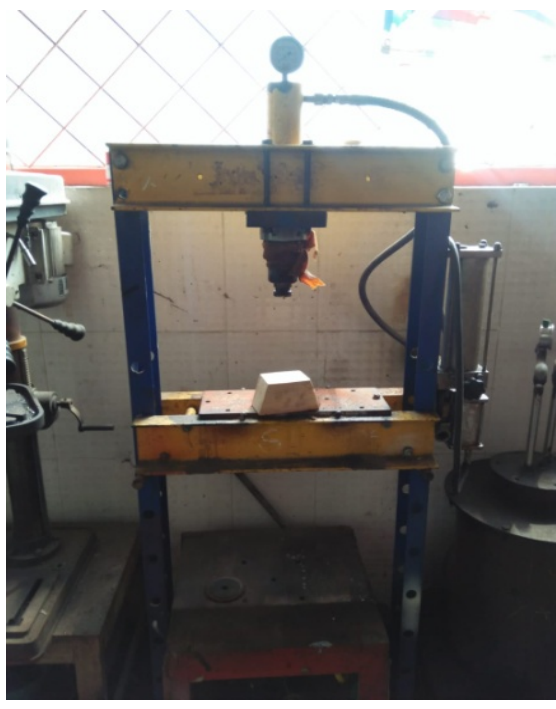

(b)

Gambar 1. (a) Mesin penggiling daun tebu dan (b)Alat pengepresan pelet daun tebu

\subsection{Metode pengambilan data}

Metode pengambilan data pada penelitian ini adalah metode densifikasi berupa peletisasi serbuk daun tebu dan diikuti metode eksperimental yaitu uji karakteristik biomassa daun tebu dengan memvariasikan ukuran serbuk daun tebu (DT) dan campuran serbuk daun dengan perekat (DTP). Variasi DT adalah $1 \mathrm{~mm}$, 1,5 mm, dan $2 \mathrm{~mm}$ dengan DTP 200 gram : 1 gram, 200 gram : 2 gram, dan 200 gram : 3 gram pada tekanan pengepresan 400 psi, dengan bagan pembuatan pelet daun tebu seperti pada Gambar 2. 


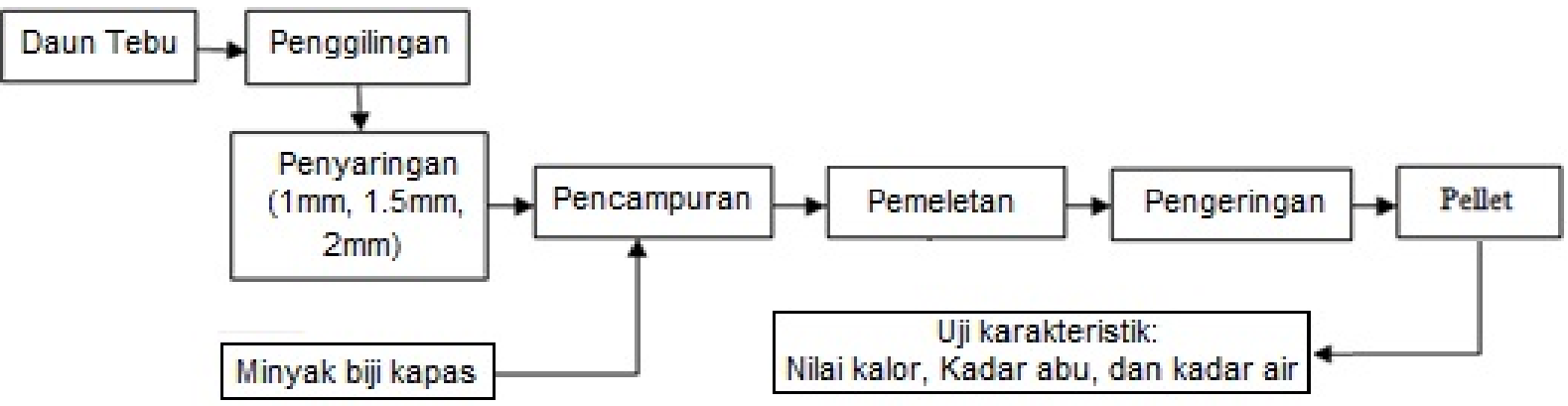

Gambar 2. Bagan pembuatan pelet daun tebu

Lokasi penelitian dilakukan di Laboratorium Energi Teknik Mesin ITN Malang yaitu proses pembuatan pelet daun tebu seperti pada Gambar 2. Pengujian nilai kalor dilakukan di Laboratorium Motor Bakar Teknik Mesin Universitas Brawijaya Malang dan pengujian kadar air dilakukan di Laboratorium Teknik Kimia Institut Teknologi Nasional Malang.

\subsection{Persamaan matematik}

a. Pengujian nilai kalor dilakukan untuk mngetahui besar nilai kalor yang dihasilkan dari pembakaran pellet dengan persamaan pada ASTM D-2015 sebagai berkut:

$\mathrm{HV}=\frac{t_{w}-e_{1}-e_{2}}{w}$

b. Pengujian kadar air dilakukan untuk mengetahui kadar air dari pellet setelah dikeringkan selama 24 jam sebelum dilakukan pembakaran dengan persamaan pada ASTM D-3173 sebagai berikut:

$\mathrm{KA}=\frac{\mathrm{BB}-\mathrm{BK}}{\mathrm{BB}} \mathrm{X} \mathbf{1 0 0} \%$

Dengan $\mathrm{KA}=$ kadar air, BB=berat bahan basah, BK=berat bahan kering

c. Pengujian kadar abu dilakukan untuk mengetahui nilai kadar abu yang dihasilkan dari pembakaran pellet dengan persamaan sebagai berikut:

Kadar Abu $=\frac{\mathbf{c}-\mathbf{b}}{\mathbf{a}} \mathbf{X 1 0 0} \%$

(3)

Dengan a=berat sampel, b=berat cawan, c=berat cawan+berat abu

\section{Hasil dan pembahasan}

\subsection{Hasil Data hasil pengujian}


Asroful Anam, dkk./Jurnal Rekayasa Mesin p-ISSN: 1411-6863, e-ISSN: 2540-7678

Vol.15|No.1|59-65|April|2020

Berdasarkan hasil penelitian didapatkan data-data pengujian seperti pada Tabel 1. Data pengujian kalor, Tabel 2. Data pengujian kadar air dan Tabel 3. Data pengujian kadar abu.

Tabel 1. Data pengujian kalor

\begin{tabular}{|c|c|c|c|c|c|c|c|}
\hline \multirow{2}{*}{ No } & \multirow{2}{*}{$\begin{array}{c}\text { Ukuran } \\
\text { Serbuk } \\
(\mathrm{mm})\end{array}$} & \multirow{2}{*}{$\begin{array}{c}\text { Rasio } \\
\text { Campuran (gr) }\end{array}$} & \multirow{2}{*}{$\begin{array}{c}\text { Massa } \\
\text { pellet (gr) }\end{array}$} & \multicolumn{4}{|c|}{ Q (cal/gr) } \\
\hline & & & & Q1 & Q2 & Q3 & Q rata-rata \\
\hline \multirow[t]{4}{*}{1} & $1 \mathrm{~mm}$ & $200: 0$ & 1 & 3.786 & 4.018 & 3.451 & 3.751 \\
\hline & & $200: 1$ & 1 & 4.276 & 3.606 & 4.044 & 3.975 \\
\hline & & $200: 2$ & 1 & 4.276 & 3.438 & 3.735 & 3.815 \\
\hline & & $200: 3$ & 1 & 3.606 & 4.301 & 3.838 & 3.914 \\
\hline \multirow[t]{4}{*}{2} & $1,5 \mathrm{~mm}$ & 200: 0 & 1 & 4.147 & 3.348 & 4.276 & 3.923 \\
\hline & & $200: 1$ & 1 & 3.220 & 3.606 & 3.709 & 3.511 \\
\hline & & $200: 2$ & 1 & 3.451 & 3.529 & 3.451 & 2.441 \\
\hline & & $200: 3$ & 1 & 3.245 & 4.044 & 4.018 & 3.768 \\
\hline \multirow[t]{4}{*}{3} & $2 \mathrm{~mm}$ & $200: 0$ & 1 & 4.378 & 4.224 & 4.404 & 4.335 \\
\hline & & 200: 1 & 1 & 4.301 & 3.760 & 3.735 & 3.932 \\
\hline & & $200: 2$ & 1 & 3.606 & 3.529 & 3.451 & 2.493 \\
\hline & & $200: 3$ & 1 & 3.812 & 3.760 & 3.786 & 3.786 \\
\hline
\end{tabular}

Tabel 2. Data pengujian kadar air

\begin{tabular}{|c|c|c|c|c|c|c|c|}
\hline \multirow{2}{*}{ No } & \multirow{2}{*}{$\begin{array}{c}\text { Ukuran } \\
\text { Serbuk } \\
\text { (mm) }\end{array}$} & \multirow{2}{*}{$\begin{array}{c}\text { Rasio } \\
\text { Campuran } \\
\text { (gr) }\end{array}$} & \multirow{2}{*}{$\begin{array}{c}\text { Massa } \\
\text { pellet } \\
\text { (gr) }\end{array}$} & \multicolumn{4}{|c|}{ Kadar Abu (\%) } \\
\hline & & & & S 1 & S 2 & S 3 & S rata - rata \\
\hline \multirow[t]{4}{*}{1} & $1 \mathrm{~mm}$ & $200: 0$ & 1 & 14 & 13 & 14 & 13,66 \\
\hline & & $200: 1$ & 1 & 14 & 15 & 12 & 13,66 \\
\hline & & $200: 2$ & 1 & 13 & 12 & 13 & 12,66 \\
\hline & & $200: 3$ & 1 & 13 & 12 & 13 & 12,66 \\
\hline \multirow[t]{4}{*}{2} & $1,5 \mathrm{~mm}$ & 200: 0 & 1 & 7 & 6 & 8 & 7 \\
\hline & & $200: 1$ & 1 & 8 & 7 & 7 & 7,3 \\
\hline & & $200: 2$ & 1 & 8 & 6 & 7 & 7 \\
\hline & & $200: 3$ & 1 & 9 & 7 & 6 & 7,3 \\
\hline \multirow[t]{4}{*}{3} & $2 \mathrm{~mm}$ & $200: 0$ & 1 & 6 & 7 & 6 & 6,3 \\
\hline & & $200: 1$ & 1 & 8 & 7 & 7 & 7,3 \\
\hline & & $200: 2$ & 1 & 8 & 6 & 7 & 7 \\
\hline & & $200: 3$ & 1 & 7 & 7 & 6 & 6,6 \\
\hline
\end{tabular}

Tabel 3. Data pengujian kadar abu

\begin{tabular}{|c|c|c|c|c|c|c|c|}
\hline \multirow{2}{*}{ No } & \multirow{2}{*}{$\begin{array}{c}\text { Ukuran } \\
\text { Serbuk } \\
\text { (mm) }\end{array}$} & \multirow{2}{*}{$\begin{array}{c}\text { Rasio } \\
\text { Campuran } \\
\text { (gr) }\end{array}$} & \multirow{2}{*}{$\begin{array}{c}\text { Massa } \\
\text { pellet (gr) }\end{array}$} & \multicolumn{4}{|c|}{ Kadar Air (\%) } \\
\hline & & & & S 1 & S 2 & S 3 & $\mathrm{~S}$ rata - rata \\
\hline \multirow[t]{4}{*}{1} & $1 \mathrm{~mm}$ & $200: 0$ & 1 & 9,8 & 9,3 & 8,5 & 9,2 \\
\hline & & $200: 1$ & 1 & 9,6 & 8,5 & 8,3 & 8,8 \\
\hline & & $200: 2$ & 1 & 10,3 & 9,5 & 9,7 & 9,8 \\
\hline & & $200: 3$ & 1 & 9,6 & 8,6 & 8,6 & 8,9 \\
\hline \multirow[t]{4}{*}{2} & $1,5 \mathrm{~mm}$ & $200: 0$ & 1 & 9,2 & 9,5 & 8,7 & 9,1 \\
\hline & & $200: 1$ & 1 & 9,9 & 7,8 & 7,5 & 8,4 \\
\hline & & $200: 2$ & 1 & 10,0 & 9,7 & 8,7 & 9,4 \\
\hline & & $200: 3$ & 1 & 9,8 & 7,5 & 8,4 & 8,5 \\
\hline 3 & $2 \mathrm{~mm}$ & $200: 0$ & 1 & 8,5 & 8,6 & 8,5 & 8,5 \\
\hline
\end{tabular}


Asroful Anam, dkk./Jurnal Rekayasa Mesin

p-ISSN: 1411-6863, e-ISSN: 2540-7678

Vol.15|No.1|59-65|April|2020

\begin{tabular}{cccccc}
$200: 1$ & 1 & 8,9 & 7,6 & 8,2 & 8,2 \\
$200: 2$ & 1 & 9,4 & 8,5 & 8,5 & 8,8 \\
$200: 3$ & 1 & 9,2 & 7,3 & 6,4 & 7,6 \\
\hline
\end{tabular}

3.2 Analisa dan pembahasan

Merujuk pada data-data hasil pengujian pelet biomassa daun tebu dituangkan pada grafik untuk memudahkan proses analisa.

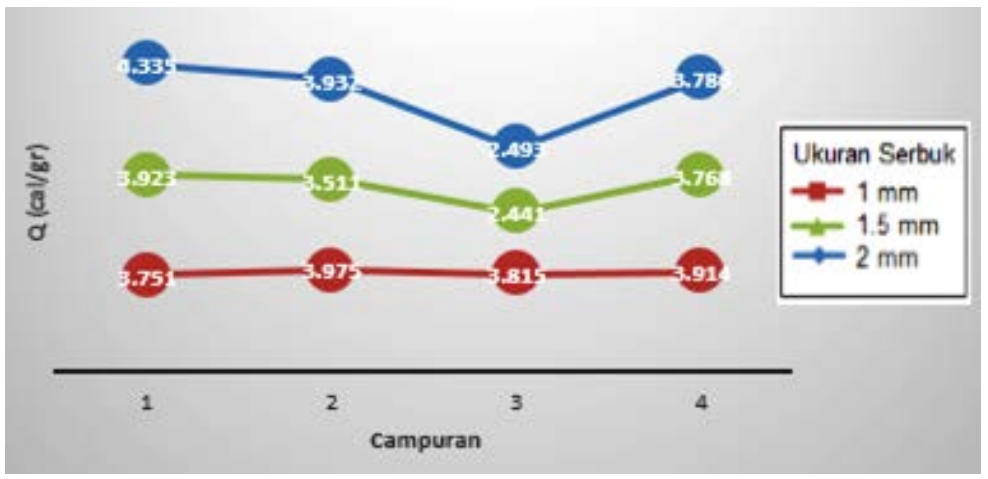

Gambar 3. Grafik pengaruh rasio campuran terhadap nilai kalor

Berdasarkan Gambar 3 ditunjukkan bahwa pada pengujian serbuk daun tebu 1mm tanpa perekat nilai kalor pada pembakarannya $3.751 \mathrm{cal} / \mathrm{gr}$; setelah dilakukan pencampuran dengan perekat, nilainya kalor tertinggi pada campuran 3 gr, sebesar $3.914 \mathrm{cal} / \mathrm{gr}$; dannilai kalor terendah pada campuran perekat 2gr, yaitu $3.815 \mathrm{cal} / \mathrm{gr}$. Sedangkan pada pengujian ukuran serbuk 1,5mm tanpa perekat menghasilkan nilai kalor tertinggi $3.751 \mathrm{cal} / \mathrm{gr}$; setelah dilakukan pencampuran dengan perekat, nilai kalor pada perekat 3gr tertinggi mencapai $3.768 \mathrm{cal} / \mathrm{gr}$; dan nilai kalor terendah dengan campuran perekat 2gr, yaitu $2.441 \mathrm{cal} / \mathrm{gr}$. Kemudian pada pengujian ukuran serbuk $2 \mathrm{~mm}$ tanpa perekatmemiliki nilai kalor tertinggi pada $3.751 \mathrm{cal} / \mathrm{gr}$; setelah dilakukan pencampuran dengan perekat menghasilkan nilai kalor tertinggi dengan campuran perekat 1 gr yaitu $3.932 \mathrm{cal} / \mathrm{gr}$; dan nilai kalor terendah pada campuran perekat 2 gr yaitu 2.493 $\mathrm{cal} / \mathrm{gr}$.

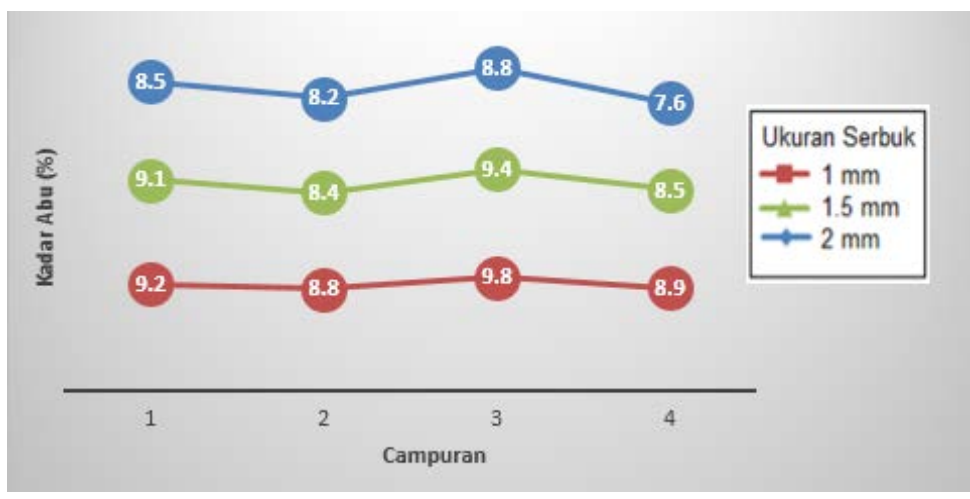

Gambar 4. Grafik pengaruh rasio campuran terhadap kadar abu

Berdasarkan Gambar 4 ditunjukkan bahwa pada pengujian ukuran serbuk $1 \mathrm{~mm}$ tanpa perekat, jumlah kadar abu adalah 9,2\%; setelah di campurkan perekat kadar abu tertinggi pada campuran 1 gr, yaitu 9,8\% dan mengalami penurunan pada pencampuran 3 gr yaitu 12,66\% dan jumlah kadar abu terendah yaitu di 88\% pada campuran 1 gr. Sedangkan pada pengujian ukuran serbuk 1,5 mm tanpa perekat 9,1\% setelah dicampur dengan perekat terjadi 
peningkatan kadar abu dan tertinggi 9,4 \% pada campuran 2 gr dan kadar abu terendah 8,4\% pada campuran 1 gr. Kemudian pada pengujian ukuran serbuk $2 \mathrm{~mm}$ tanpa perekat, jumlah kadar abu 8,5\%; setelah di campur dengan perekat jumlah kadar abu tertinggi pada campuran 2 gr sebesar 8,8\% dan kadar abu terendah 7,6\%.

\section{Kesimpulan}

Berdasarkan hasil penelitian karakteristik limbah daun tebu dapat di simpulkan bahwa ukuran serbuk daun tebu dan variasi campuran serbuk daun tebu dengan perekat minyak biji kapas mempengaruhi karakteristik limbah daun tebu sebagai bahan bakar biomassa, baik nilai kalor, kandungan air maupun kadar abu. Nilai kalor tertinggi pada ukuran serbuk 2 mm, yaitu 3975,01 cal/gr pada rasio campuran 1; kadar abu paling baik pada ukuran serbuk $2 \mathrm{~mm}$ yaitu 6,6\% pada rasio campuran 3 dan kadar air paling sedikit ukuran serbuk 1 mm yaitu 9,8\% pada rasio campuran 2.

\section{Daftar Pustaka}

[1] Direktorat Jenderal EBTKE, Kemeterian ESDM RI, Ruang Energi. http://ebtke.esdm.go.id/post/2020/02/18/2480/ ruang.energi.energi.terbarukan.janjikan.karir.masa.depan?lang=en. Ruang Energi: Green Jobs Solo; 2020 (Diakses pada tanggal 14 Februari 2020).

[2] Silalahi.Penelitian pembuatan briket kayu dari serbuk gergajian kayu.Bogor: Hasil Penelitian Industri DEPERINDAG; 2000.

[3] Kemeterian ESDM RI, Potensi EBT, https://www.esdm.go.id/id/media-center/arsip-berita/potensi-energi-baruterbarukan-ebt-indonesia. Jakarta; 2008 (Diakses pada tanggal 14 Februari 2020).

[4] Coniwanti.Studi komparasi nilai kalor briket serbuk gergaji kayu jati dan kulit kacang, Indonesia: Universitas Sebelas Maret; 2012.

[5] Motghare, K.A., Ajit P.R., Kaila L.W., Nitin K.L. Comparative study of different waste biomass for energy application. Waste Management. 2016 August;47: p. 40.

[6] Alchris Woo Go, Angelique T. Conag. Utilizing sugarcane leaves/straws as source of bioenergy in the Philippines: A case in the Visayas Region. Renewable Energy. 2018 September;132: p. 1230.

[7] Kumar, M., Shivesh Sabbarwal, P.K., Mishra, S.N., Upadhyay. Thermal degradation kinetics of sugarcane leaves (Saccharum officinarum L)using thermo-gravimetric and differential scanning calorimetric studies. 2019January;279: p. 262.

[8] Angelique T. Conag., Jaye Earl R. Villahermosa, Luis K. Cabatingan, Alchris W. Go.Energy densification of sugarcane leaves through torrefaction underminimized oxidative atmosphere. Energy for Sustainable Development. 2017 Desember; 42: p. 160.

[9] Indonesian Coal Mining Association. http://www.1greenhouse.com/en3/848-745/Batu-bara_27597_1greenhouse. html. Book of Indonesian Encyclopedia, 1998 (Diakses pada tanggal 14 Februari 2020).

[10] Putro, S., Musabbikhah, Suranto. Variasi temperatur dan waktu karbonisasi untuk meningkatkan nilai kalor dan memperbaiki sifat proximate biomassa sebagai bahan pembuat briket yang berkualitas. Simposium Nasional RAPI XIV; 2015; Semarang, Indonesia. FT UMS; 2015. ISSN 1412-9612. p. M-282.

[11] Syamsiro, M. Peningkatan Kualitas Bahan Bakar Padat Biomassa Dengan Proses Densifikasi dan Torefaksi. Jurnal Mekanika dan Sistem Termal. 2016 April; 1(1): p. 7. 